Document downloaded from:

http://hdl.handle.net/10251/146276

This paper must be cited as:

Qian, G.; González Albuixech, VF.; Niffenegger, M. (08-2). Effects of embedded cracks and residual stresses on the integrity of a reactor pressure vessel. Engineering Failure Analysis. 90:451-462. https://doi.org/10.1016/j.engfailanal.2018.04.009

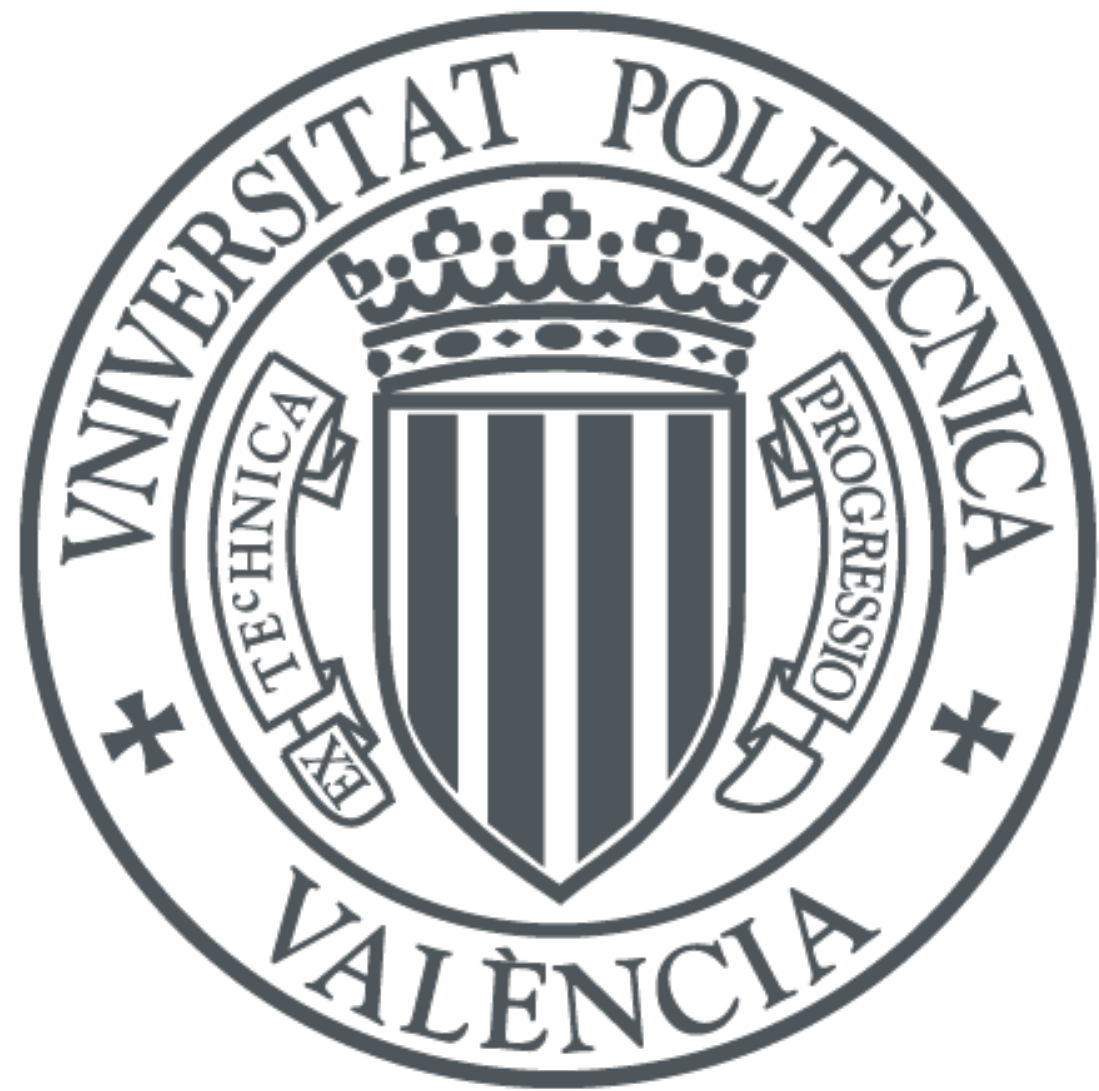

The final publication is available at

https://doi.org/10.1016/j.engfailanal.2018.04.009

Copyright Elsevier

Additional Information 


\section{Accepted Manuscript}

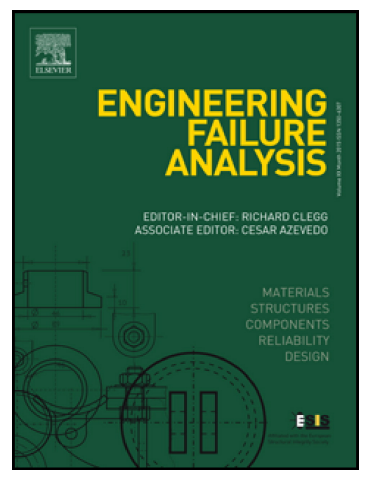

Guian Qian, V.F. González-Albuixech, Markus Niffenegger

PII:

S1350-6307(18)30073-6

DOI:

doi:10.1016/j.engfailanal.2018.04.009

Reference:

EFA 3437

To appear in:

Engineering Failure Analysis

Received date:

15 January 2018

Revised date:

28 February 2018

Accepted date:

5 April 2018

Please cite this article as: Guian Qian, V.F. González-Albuixech, Markus Niffenegger, Effects of embedded cracks and residual stresses on the integrity of a reactor pressure vessel. The address for the corresponding author was captured as affiliation for all authors. Please check if appropriate. Efa(2018), doi:10.1016/j.engfailanal.2018.04.009

This is a PDF file of an unedited manuscript that has been accepted for publication. As a service to our customers we are providing this early version of the manuscript. The manuscript will undergo copyediting, typesetting, and review of the resulting proof before it is published in its final form. Please note that during the production process errors may be discovered which could affect the content, and all legal disclaimers that apply to the journal pertain. 


\title{
Effects of embedded cracks and residual stresses on the integrity of a reactor pressure vessel
}

\author{
Guian Qian $^{1, *}$, V.F. González-Albuixech ${ }^{2}$, Markus Niffenegger ${ }^{1}$ \\ ${ }^{1}$ Paul Scherrer Institute, Nuclear Energy and Safety Department, Laboratory for Nuclear Materials, Villigen \\ PSI, Switzerland \\ ${ }^{2}$ CIIM Universitat Politècnica de València. Camino de Vera, s/n 46022 Valencia, Spain
}

*Corresponding author

Guian Qian

Tel. +41563102865

Fax. +41563102199

E-mail address: guian.qian@psi.ch

Paul Scherrer Institute

Nuclear Energy and Safety Research Department, Laboratory for Nuclear Materials, OHSA/06

5232 Villigen PSI, Switzerland 


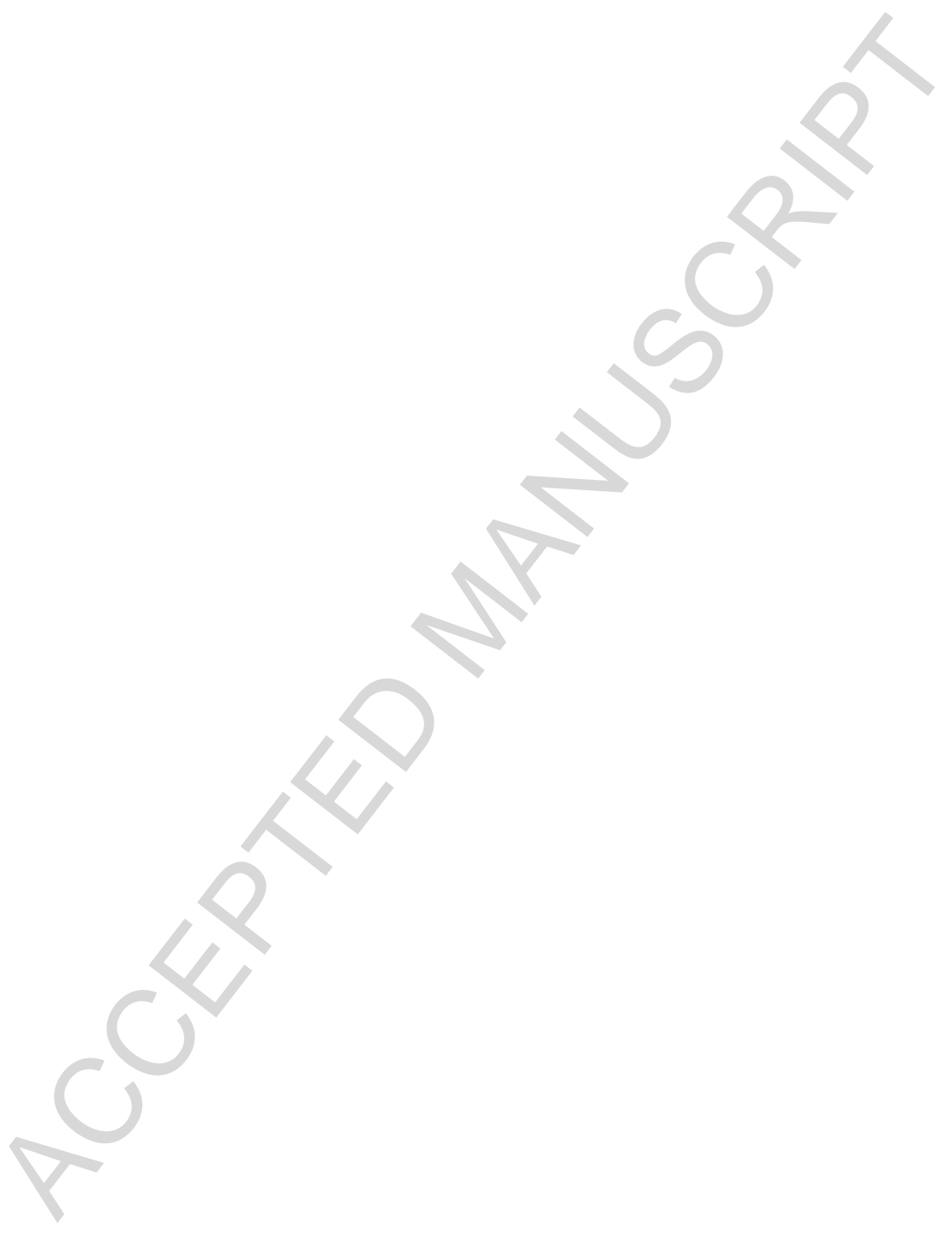




\section{Abstract}

One potential challenge to the integrity of the reactor pressure vessel (RPV) of a pressurized water reactor is posed by a pressurized thermal shock (PTS), which is associated with rapid cooling of sections of the hot and still pressurized RPV by injection of relatively cold emergency coolant. PTS transients lead to high tensile circumferential and axial stresses in the RPV wall. If the stress intensity factor (SIF) is large enough, a critical crack may grow. Thus, the RPV has to be assessed against cleavage fracture.

In this paper, two kinds of embedded cracks, i.e. semi-elliptical and elliptical crack with depth of $17 \mathrm{~mm}$ and length of $102 \mathrm{~mm}$ are considered. The extended finite element method (XFEM) is used to model such postulated cracks. The embedded crack with tip in the cladding/base interface causes a high $\mathrm{K}_{\mathrm{I}}$. This is due to the stress discontinuities at the interface between the materials. In the FAVOR (probabilistic fracture mechanics code) calculation, for such cracks the point closest to the inner surface is considered in order to be conservative. However, due to the highly ductile cladding material, it is unlikely that the embedded crack will propagate through the cladding. Thus, it is more appropriate to consider the outer surface point of the crack front.

The effect of welding residual stress and cladding/base interface residual stress on the crack driving force is studied. Surface cracks are assumed in the study of residual stresses. Results show that considering realistic welding residual stresses may increase $\mathrm{K}_{\mathrm{I}}$ by about $5 \mathrm{MPa} \cdot \mathrm{m}^{0.5}$, while the cladding/base interface residual stress has a negligible effect on $\mathrm{K}_{\mathrm{I}}$. The reason is that the cladding residual stress is only localized to the interface and it decreases significantly through the vessel wall. Considering welding residual stress increases the Weibull stress and fracture probability of the RPV.

Keywords: reactor pressure vessel, pressurized thermal shock, welding residual stress, embedded crack 


\section{Nomenclature}

$a$

$K_{I}$

$K_{I c}$

$m, \sigma_{0}$

$M_{m}$

$M_{b}$

$P$

$Q$

$t$

$T$

$V_{0}$

$V_{p l}$

$x$

$\sigma_{R}$

$\sigma_{m}$

$\sigma_{b}$

$\sigma_{w}$

$\sigma_{t h}$

$\sigma_{l}$

CRS crack depth, mm

Mode I linear elastic stress intensity factor, $\mathrm{MPa} \cdot \mathrm{m}^{0.5}$

material fracture toughness, $\mathrm{MPa} \cdot \mathrm{m}^{0.5}$

model parameters known as Weibull modulus

free-surface correction for membrane stress

free-surface correction for bending stress

fracture probability

crack shape correction factor for stress intensity factor calculation

vessel wall thickness, $\mathrm{mm}$

temperature, ${ }^{\circ} \mathrm{C}$

elementary volume representing the mean volume occupied by each micro-crack in a solid, $\mathrm{mm}^{3}$

volume of the plastic deformation zone as the cleavage fracture process

zone, $\mathrm{mm}^{3}$

distance from the inner surface of the vessel, $\mathrm{mm}$

residual stress, $\mathrm{MPa}$

membrane stress, MPa

bending stress, $\mathrm{MPa}$

Weibull stress, MPa

threshold stress, MPa

maximum tensile principal stress, $\mathrm{MPa}$

cladding residual stress 
FEM

MBLOCA

PTS

RPV

SIF

SBLOCA

WRS

XFEM finite element method

medium break loss-of-coolant accident

pressurized thermal shock

reactor pressure vessel

stress intensity factor

small break loss-of-coolant accident

welding residual stress

extended finite element method 


\section{Introduction}

The integrity of the reactor pressure vessel (RPV) of a nuclear power plant has to be assured throughout the whole lifetime of the plant, and the proof of the exclusion of brittle failure of the RPV for all possible load cases is an important task in the safety assessment. During operation, certain abnormal conditions could result in the so called pressurized thermal shock (PTS), i.e. rapid cooling of sections of the hot and still pressurized RPV by injection of relatively cold emergency coolant. Brittle failure under PTS conditions and increasing neutron embrittlement during operation is generally considered to be the major threat to RPV integrity. Thus, the PTS analysis has to be performed according to the material property obtained from the surveillance program.

During the last two decades, substantial progress has been achieved in the safety assessment of RPVs under PTS loadings [1-13]. Integrity analysis of a model RPV subjected to a small break loss-of-coolant accident (SBLOCA) and a medium break loss-of-coolant accident (MBLOCA) is performed by assuming crack depths of two times the nondestructive examination limit [1-2]. The constraint effect of crack tip on the fracture toughness is also analyzed in $[1,2]$. Elastic-plastic analysis and cleavage fracture analysis have been performed in RPV materials considering different loading transients [3-7]. Chou et al. [8] performed a probabilistic analysis for a RPV considering the uncertainty of crack distributions and fracture toughness according to the US Nuclear Regulatory Commission [9]. Testing of fracture toughness in the ductile-to-brittle transition temperature is documented in [10]. The solutions of crack driving force and modeling of fracture toughness are presented [11, 12]. The general procedure for structural integrity assessment of a RPV subjected to a PTS is briefly introduced. In the structural integrity analysis, firstly the temperature distribution is calculated through the RPV wall for a certain transient. The input parameters, which consist of water temperature, pressure and heat transfer coefficient between water and the inner wall of the RPV, stem from thermal hydraulic calculation (e.g. RELAP). Based on the temperature field, the circumferential and axial stress histories for the whole transient are calculated. Finally, cracks with different depths and orientations are assumed in the beltline region and the 
calculation of SIFs is performed. Different models, such as the ASME model, the Master Curve and the FAVOR model [13], are used to characterize fracture toughness of the material at different temperatures by using the material chemical composition and the neutron fluence. In the integrity analysis of the RPV, both deterministic and PFM analyses are performed. In fact, the probabilistic analysis is always based on a deterministic analysis. In the deterministic method the maximum allowed $\mathrm{RT}_{\mathrm{NDT}}$ to exclude crack initiation is determined.

It is widely studied that postulated embedded cracks close to the inner-surface of an RPV contribute significantly to the conditional probability of cleavage fracture of the RPV during the PTS events. Therefore, it is necessary that an accurate $\mathrm{K}_{\mathrm{I}}$ computation for embedded cracks is available. In the FAVOR code [13] developed by ORNL, the crack tip close to the inner surface of the vessel wall is considered in order to be conservative. However, the propagation of the crack tip close to the inner surface is questionable due to the ductile material of the cladding. Thus, $\mathrm{K}_{\mathrm{I}}$ calculation of the embedded crack is presented and discussed using FAVOR and extended finite element methods (XFEM).

In this paper, the effect of welding residual stress and cladding/base interface residual stress on the crack driving force is studied. The welding process to connect different RPV rings together creates the welding residual stress. Finite element analysis was applied to compare the crack driving force obtained using residual stress distribution formulas and the stress free temperature model.

The paper is organized as follows: The first part is introduction. The second part presents the fracture mechanics analysis for embedded cracks. Then follow the effects of residual stress and cladding on $\mathrm{K}_{\mathrm{I}}$. The last part is conclusions. In the modeling of embedded cracks in Figs.1, 2,4 (partly),5,7,8, XFEM is used to calculate $\mathrm{K}_{\mathrm{I}}$. In Figs. 6 ,4 (partly), 12, FAVOR is used to calculate $\mathrm{K}_{\mathrm{I}}$. In the analysis of residual stress in Figs. 10 and 11, 3D FEM is used to analyze $\mathrm{K}_{\mathrm{I}}$.

\section{Fracture Mechanics analysis for embedded cracks}


In FAVOR code, the stress intensity factor (SIF) of an embedded crack is calculated by the EPRI model in the ASME procedure [13]. It is a weight function method based on the resolution of nonlinear applied stresses through the RPV wall thickness into the linear superposition of approximate membrane and bending stress components. It is expressed as

$$
K_{I}=\sqrt{\frac{\pi a}{Q}}\left(M_{m} \sigma_{m}+M_{b} \sigma_{b}\right)
$$

In order to simplify the modelling, SIF can also be calculated by the interaction integral using XFEM, which enriches the finite element approach space with special functions that are able to describe the discontinuity and introduce the singular behaviour associated with the crack front, and makes its analysis, up to a certain point, independent of the mesh [14]. The essential idea in XFEM is to use a displacement field approximation that can model any crack face discontinuity and the near crack-tip asymptotic stress field. As a consequence it is not necessary to modify the mesh to consider a specific crack; at most, moderate refinement must be introduced around the crack to achieve good accuracy. XFEM is implemented in Abaqus [15]. In this study, FAVOR and XFEM are used to calculate the SIFs based on the reference transient.

Two kinds of embedded cracks, i.e. semi-elliptical and elliptical crack with depth of $17 \mathrm{~mm}$ and length of 102 mm are considered, as shown in Fig. 1. The depth of the crack is two times the nondestructive detection limit, according to the German standard KTA 3201.2. The two kinds of embedded cracks in Fig. 1 are totally different crack types. The crack shown in Figure 1a is an underclad crack and the crack shown in Figure 1b is a subsurface (embedded) crack in base metal. The embedded crack in Fig.1b is considered in FAVOR but the underclad crack isn't considered in FAVOR. However, according to the report [16], the underclad crack is found in European reactors. In order to study the integrity of the underclad on the RPV, an underclad crack is postulated in this study. The vessel has the inner radius of $1668.5 \mathrm{~mm}$ and thickness of $171 \mathrm{~mm}$ including a 5 mm cladding. XFEM is used to model such cracks. The assembling of the RPV and the embedded crack and the mesh are shown in Fig. 2. The submodeling technique is used, as shown in Fig. 2. SIFs for crack front point A 
and $\mathrm{B}$ are calculated. The postulated transients considered in this paper, as shown in Fig.3, are MBLOCA and SBLOCA described in [1, 2]. RPV material properties are described in $[1,2]$ and presented in Table 1 . The results from XFEM are also compared with those from FAVOR for point A, as shown in Fig. 4. A good agreement is obtained, which validated the results calculated by XFEM. In Fig. 5, it is shown that the embedded crack with tip in the cladding/base interface (point A) causes a high $\mathrm{K}_{\mathrm{I}} \cdot \mathrm{K}_{\mathrm{I}}$ for point $\mathrm{A}$ is between $50 \%-100 \%$ higher than that for point $\mathrm{B}$, which is due to the stress discontinuities at the interface between the materials. This confirms the conservative assumption in the FAVOR code. In the FAVOR calculation, for such cracks the point closest to the inner surface is considered in order to be conservative. The SIFs are compared with fracture toughness of the base material and cladding of the RPV. SIFs for both surface and embedded cracks are calculated. The surface crack and the depth of the crack are according to the German standard KTA 3201.2. $\mathrm{K}_{\mathrm{Ic}}$ database of cladding material (both irradiated and unirradiated) are collected from $[17,18]$. It is shown in Fig. 6 that SIFs at the tip closest to the inner surface of the RPV is higher than the $\mathrm{K}_{\mathrm{Ic}}$ of the base material while lower than that of cladding. This indicates that the embedded crack may initiate in the cladding direction because of a high SIF. However, due to the highly ductile cladding material, it is unlikely that the embedded crack will propagate through the cladding. Thus, it is more appropriate to consider the outer surface point B of the crack front in the integrity assessment. In FAVOR, If the SIF of an embedded crack (completely contained in the base material) exceeds the fracture toughness of the base material, then the following is assumed: The crack initiates in cleavage fracture in the base material; The embedded flaw instantaneously becomes an infinite surface crack, i. e., the cladding above the crack is assumed to have failed completely and the crack to have extended lengthwise, either in the axial or circumferential directions. From this study, a detailed crack propagation is needed. It is noted that in the integrity assessment of core region of RPV, the important embedded cracks are cracks with distances to the inner surface smaller than $3 / 8$ of the wall thickness. In this study, we considered the most 
critical case of the embedded cracks. The embedded crack located close to the inner surface of the RPV wall is more critical due to the higher $\mathrm{K}_{\mathrm{I}}$ and lower $\mathrm{K}_{\mathrm{Ic}}$.

In a general 3D stress state, the critical crack orientation is not obvious as in axisymmetric cases where it is sufficient to analyse circumferential and axial cracks lying perpendicular to the principal stress directions. We therefore performed an additional analysis of a crack which is inclined by 45 degree to the axial direction of the RPV. In addition a planar crack was postulated. With a planar crack we mean that the crack is parallel to the inner surface of the vessel, similar to the hydrogen flakes found in Belgian RPVs. Both surface and embedded cracks have been found in US research reactors, according to [16]. It is shown in Fig. 7 that the SIF for a 45 degree inclined crack is between that for axial and circumferential cracks. However, the SIF for the planar crack is much lower and this crack is not likely to propagate, as shown in Fig. 8. It is noted that the negative K in Fig. 8 may be due to crack closure in the starting stage of the transient.

\section{Effects of residual stress on $K_{I}$}

The effect of welding residual stress and cladding/interface residual stress is studied. According to IAEA [19], the welding residual stress in the welds along the vessel wall is expressed as

$\sigma_{\mathrm{R}}=56 \cdot \cos \left(\frac{2 \pi \mathrm{x}}{\mathrm{t}}\right)(\mathrm{MPa})$

where $t$ is the RPV thickness without cladding, $x$ is the distance starting from the inner surface of the vessel wall.

A similar formula is used in FAVOR [13] to account for the welding residual stress as $\sigma_{\mathrm{R}}=44 \cdot \cos \left(\frac{2 \pi \mathrm{x}}{\mathrm{t}}\right)(\mathrm{MPa})$

In this study, both equations are used to study the effect of welding residual stress. The prescribed residual stresses are applied to the ABAQUS models with a user subroutine which assigned stress at material points based on their radial and circumferential location. The stress was initialized with the model at room 
temperature, and a subsequent analysis step allowed the stresses to self-equilibrate. A three-dimensional, axisymmetric model is built with linear elastic, temperature dependent, material properties applied for the base and cladding, as shown in Fig. 9. A semi-elliptical crack with depth of $17 \mathrm{~mm}$ is assumed and $\mathrm{K}_{\mathrm{I}}$ of the deepest point in the crack front is calculated. As shown in Fig. 10, the welding residual stress results in a $\mathrm{K}_{\mathrm{I}}$ of about 5 $\mathrm{MPa} \cdot \mathrm{m}^{0.5}$ along the crack front for both axial and circumferential cracks.

Moreover, the modified Beremin model is used to scale fracture toughness in different specimens. As a local approach to fracture, Beremin model [20] is essentially a two-parameter Weibull distribution as below:

$\mathrm{P}=1-\exp \left[-\left(\int_{V_{p l}} \sigma_{1}^{m} d V / V_{0}\right) / \sigma_{0}^{m}\right]=1-\exp \left[-\left(\sigma_{W} / \sigma_{0}\right)^{m}\right]$,

with $\sigma_{W}=\left(\int_{V_{p l}} \sigma_{1}^{m} d V / V_{0}\right)^{1 / m}$

where $\mathrm{P}$ is the cumulative probability of fracture, $\mathrm{V}_{\mathrm{pl}}$ denotes the volume of the plastic deformation zone as the cleavage fracture process zone, $\mathrm{m}$ and $\sigma_{0}$ are the two model parameters known as Weibull modulus and the scale parameter, respectively, $\sigma_{1}$ is the maximum tensile principal stress, $\mathrm{V}_{0}$ is an elementary volume representing the mean volume occupied by each micro-crack in a solid, $\mathrm{dV}$ is the differential volume. In order to consider the plastic deformation effect, the cumulative failure probability formulation is modified to adopt a fixed-value threshold stress $\left(\sigma_{\mathrm{th}}\right)$ by Gao et al. [21],

$P=1-\exp \left[-\left(\frac{\sigma_{W}-\sigma_{t h}}{\sigma_{0}-\sigma_{t h}}\right)^{m}\right]$

According to the European program [22], the calibrated parameters for this RPV material are $\mathrm{m}=6.36, \sigma_{\mathrm{th}}=1546$ $\mathrm{MPa}, \sigma_{0}=2076 \mathrm{MPa}, \mathrm{V}_{0}=0.001 \mathrm{~mm}^{3}$. The integration zone is volume where the von Mises stress is over two times the yielding stress. It is shown in Fig. 11 (a) that the Weibull stresses $\sigma_{w}$ for the case with WRS is greater than that for the case without WRS. $\sigma_{\mathrm{w}}$ captures the stress and strain distributions ahead of the crack tip at the 
same J. The probability of cleavage initiation for the RPV with WRS is calculated. It is clear in Fig. 11 (b) that the RPV with WRS has a higher failure probability due to the increasing of $\mathrm{K}_{\mathrm{I}}$ by WRS.

The welding process to build the cladding on the base material causes residual stresses, partly according to the different thermal expansion of the two materials. In FAVOR, it is assumed that the residual stress at room temperature is $146.9 \mathrm{MPa}[13,23]$. The effect of welding residual stress and cladding residual stress is studied with FAVOR and the result for $\mathrm{K}_{\mathrm{I}}$ is shown in Fig. 12 (a). It is shown that considering the cladding residual stress has a negligible effect on $\mathrm{K}_{\mathrm{I}}$ for a surface crack. The reason is that the cladding residual stress only is localized to the interface and it decreases significantly through the vessel wall. It is notice that this analysis is based on the single crack calculation according to the German KTA rule. However, it has been shown [24] that a very shallow surface which just penetrates the cladding into the base material is highly influenced by the cladding. This very shallow flaw can demonstrate the highest probability of cleavage initiation. Thus, in this case, cladding residual stress plays a very important role on $\mathrm{K}_{\mathrm{I}}$ and the fracture probability.

\section{Effects of cladding on $K_{I}$}

In 3D FE calculations the question raised is whether the relatively thin cladding (austenitic stainless steel) has to be modelled, which causes problems due to the large difference in size of the different parts in the model, or whether it could be neglected.

The effect of cladding on $\mathrm{K}_{\mathrm{I}}$ is therefore studied in Fig. 12 (b). The comparison of $\mathrm{K}_{\mathrm{I}}$ and $\mathrm{K}_{\mathrm{Ic}}$ shows an overlap between $\mathrm{K}_{\mathrm{I}}$ and $\mathrm{K}_{\mathrm{Ic}}$, meaning that crack initiation may occur in the PTS transient. Considering the residual stress will increase $\mathrm{K}_{\mathrm{I}}$ and thus increase the crack initiation probability of the RPV. It is shown that neglecting the cladding leads to an increase of peak $\mathrm{K}_{\mathrm{I}}$ of about $2 \mathrm{MPa} \cdot \mathrm{m}^{0.5}$ and a temperature shift of about $-15^{\circ} \mathrm{C}$. We thus conclude that neglecting the cladding is a conservative approximation based on analyses of the single surface crack. It should be noted that a very shallow surface which just penetrates the cladding into the base material is highly influenced by the cladding [23]. For this very shallow flaw neglecting the cladding is a non- 
conservative approximation. However, our assumption of the crack is according to the German KTA rule, which assumes the crack has a depth of $1 / 10$ of the vessel wall thickness.

\section{Conclusions}

Based on this study, the following conclusions are drawn:

1. For the embedded crack, $\mathrm{K}_{\mathrm{I}}$ for point $\mathrm{A}$ is between $50 \%-100 \%$ higher than that for point $\mathrm{B}$. However, crack propagation through the cladding material is not likely, which confirms the conservative assumption in the FAVOR code.

2. The SIF for a 45 degree inclined crack is between that for axial and circumferential cracks. However, the SIF for the planar crack is much lower and this crack is not likely to propagate.

3. Considering welding residual stresses increase $\mathrm{K}_{\mathrm{I}}$ by about $5 \mathrm{MPa} \cdot \mathrm{m}^{0.5}$ (This is about $5 \%$ the peak $\mathrm{K}_{\mathrm{I}}$ for the surface crack.) and the cladding residual stress has a negligible effect on $\mathrm{K}_{\mathrm{I}}$. Neglecting the cladding is a conservative approximation for the crack has a depth of $1 / 10$ of the vessel wall thickness. It should be noted that a very shallow surface which just penetrates the cladding into the base material is highly influenced by the cladding. For this very shallow flaw neglecting the cladding is a non-conservative approximation.

4. Considering welding residual stress increases the Weibull stress and fracture probability of the RPV by about $20 \%$ for $\mathrm{K}_{\mathrm{I}}=100 \mathrm{MPa} \mathrm{m}^{0.5}$.

\section{Acknowledgements}

The authors are grateful for the financial support of the PROBAB Project provided by the Swiss Federal Nuclear Safety Inspectorate (ENSI) (DIS-Vertrag Nr. H-100668). V.F. González-Albuixech is thankful for the research program Juan de la Cierva Incorporación 2015, IJCI-2015-23245, financed by the Spanish Ministerio de Economía, Industría y Competitividad. 


\section{References}

1. Qian G, Gonzalez-Albuixech VF, Niffenegger M. In-plane and out-of-plane constraint effects under pressurized thermal shocks. Int J Solids Struc 2014; 6:1311-21.

2. Qian G, Niffenegger, M. Integrity analysis of a reactor pressure vessel subjected to pressurized thermal shocks by considering constraint effect. Eng Fract Mech 2013; (112-113): 14-25.

3. Qian XD, Jr. RH, Yin SJ, Bass R. Cleavage fracture modeling of pressure vessels under transient thermomechanical loading. Eng Fract Mech 2008; 75: 4167-89.

4. Sun X, Chai G, Bao Y. Elastic and elastoplastic fracture analysis of a reactor pressure vessel under pressurized thermal shock loading. Eur J Mech A - Solid. 2017;66:69 - 78.

5. Yu M, Luo Z, Chao YJ. Correlations between Charpy V-notch impact energy and fracture toughness of nuclear reactor pressure vessel (RPV) steels. Eng Fract Mech 2015; 147: 187-202

6. Hohe J, Brand M, Siegele D. Behaviour of sub - clad and through - clad cracks under consideration of the residual stress field. Eng Fract Mech 2010; 77:217 - 228.

7. Keim E, Schmidt C, Schöpper A, Hertlein R. Life management of reactor pressure vessels under pressurized thermal shock loading: deterministic procedure and application to Western and Eastern type of reactors. Int $\mathbf{J}$ Pres Ves Piping 2001; 78: 85-98.

8. Chou HW, Huang CC. Effects of fracture toughness curves of ASME Section XI - Appendix G on a reactor pressure vessel under pressure-temperature limit operation. Nucl Eng Des 2014; 280: 404-412.

9. U.S. Nuclear Regulatory Commission, Technical Basis for Revision of the Pressurized Thermal Shock (PTS) Screening Limit in the PTS Rule (10 CFR 50.61), NUREG-1806, Vol. 1, US NRC, Washington (2007).

10. ASTM-E1921-02, 1997. Test method for determination of reference temperature, $\mathrm{T}_{0}$, for ferritic steels in the transition range. 
11. Wang X. Elastic T-stress solutions for semi-elliptical surface cracks in finite thickness plates. Eng Fract Mech 2003; 70: 731-56.

12. Zhu XK, Joyce JA. Review of fracture toughness (G, K, J, CTOD, CTOA) testing and standardization. Eng Fract Mech 2012; 85: 1-46.

13. Williams PT, Dickson TL, Yin S. Fracture Analysis of Vessels - Oak Ridge FAVOR, v12.1,Computer Code: Theory and Implementation of Algorithms, Methods, and Correlations, ORNL/TM-2012/567, Oak Ridge National Laboratory, Oak Ridge, TN, November 2012.

14. Moës, N., Dolbow, J., Belytschko, T. A finite element method for crack growth without remeshing. Int. J Numer. Methods Engng 1999; 46: 131-150.

15. Hibbitt, Karlsson, Sorensen, 2013. Abaqus 6.13.3 Manual.

16. EricksonKirk MT, Dickson TL. Recommended Screening Limits for Pressurized Thermal Shock (PTS), 2010,NRC, NUREG-1874.

17. Brumovsky M, Kytka M., Kopriva R. Cladding in RPV integrity and Lifetime Evaluation. Procedia Engineering, 2015;130: 1544-53.

18. Viehrig H.W., Altstadt E., Houska M. Radiation response of the overlay cladding from the decommissionedWWER-440 Greifswald Unit 4 reactor pressure vessel. Nucl Eng Des 2015; 286: 227-36.

19. International atomic energy agency, 2010. Pressurised thermal shock in nuclear power plants: good practices for assessment, IAEA, Austria, IAEA-TECDOC-1627.

20. Beremin F, 1983. A Local Criterion for Cleavage Fracture of a Nuclear Pressure Vessel Steel. Metall Trans A 14A, 2277-87.

21. Gao, X., Zhang, G., and Srivatsan, T. S. Prediction of cleavage fracture in ferritic steels: A modified Weibull stress model. Mater. Sci. Eng., A 2005;394:210-219.

22. Hümmer M., Keim E., Hofmann H. TIMES: An international project on transferability of fracture toughness 
values for irradiated RPV steels. Proceedings of the PVP, July 22-26, 2007 ASME Pressure Vessels and Piping Division Conference, San Antonio, Texas, USA

23. Kusnick J., Kirk M., Bass B., Williams P., Dickson T. Effect of cladding residual stress modeling technique on shallow flaw stress intensity factor in a reactor pressure vessel. Proceedings of ASME PVP 2015.

24. Bass B., Dickson T, Williams P, Klasky H, Jr RH. The Effect of Shallow Inside-Surface-Breaking Flaws on the Probability of Brittle Fracture of Reactors Subjected to Postulated and Actual Operational Cool- Down Transients: A Status Report, ORNL/TM-2015/59531/REV-01, Oak Ridge National Laboratory, February 2016. 
Tab. 1 Thermo-mechanical properties of the base material and cladding of the RPV.

\begin{tabular}{|c|c|c|c|c|c|c|c|c|c|c|c|c|}
\hline \multirow[b]{2}{*}{ Temperature $\left[{ }^{\circ} \mathrm{C}\right]$} & \multicolumn{6}{|c|}{ Base material } & \multicolumn{6}{|c|}{ Cladding } \\
\hline & 0 & 20 & 100 & 200 & 300 & 400 & 0 & 20 & 100 & 200 & 300 & 400 \\
\hline Elastic modulus $\left[10^{3} \mathrm{MPa}\right]$ & 206 & 206 & 199 & 190 & 181 & 172 & 200 & 200 & 194 & 186 & 179 & 172 \\
\hline $\begin{array}{l}\text { Mean linear thermal expansion } \\
\text { coefficient }\left[10^{-6}{ }^{\circ} \mathrm{C}^{-1}\right]\end{array}$ & 10.3 & 10.3 & 11.1 & 12.1 & 12.9 & 13.5 & 16 & 16 & 16 & 17 & 17 & 18 \\
\hline Thermal conductivity $[\mathrm{W} /(\mathrm{m} \cdot \mathrm{K})]$ & 44.4 & 44.4 & 44.4 & 43.2 & 41.8 & 39.4 & 15 & 15 & 16 & 17 & 19 & 21 \\
\hline Specific heat capacity $[\mathrm{J} /(\mathrm{kg} \cdot \mathrm{K})]$ & 450 & 450 & 490 & 520 & 560 & 610 & 500 & 500 & 500 & 540 & 540 & 590 \\
\hline Density $\left[10^{3} \mathrm{~kg} / \mathrm{m}^{3}\right]$ & 7.6 & 7.6 & 7.6 & 7.6 & 7.6 & 7.6 & 7.6 & 7.6 & 7.6 & 7.6 & 7.6 & 7.6 \\
\hline Poisson's ratio & & 0.3 & & & & & $b^{\prime}$ & 0.3 & & & & \\
\hline $\begin{array}{l}\text { Yield stress of the unirradiated } \\
\text { material }[\mathrm{MPa}]\end{array}$ & & 449.3 & & & & & & & & & & \\
\hline Stress free temperature $\left[{ }^{\circ} \mathrm{C}\right]$ & \multicolumn{12}{|c|}{280.3} \\
\hline
\end{tabular}




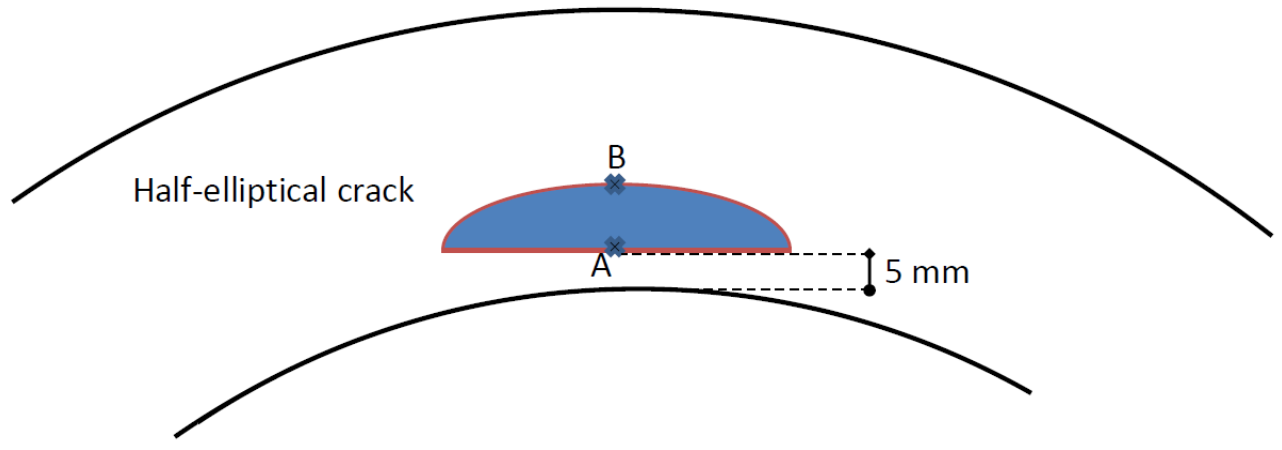

Fig. 1a Half-elliptical (Semi-elliptical) crack postulated in the study, both point A and B are considered in the calculation.

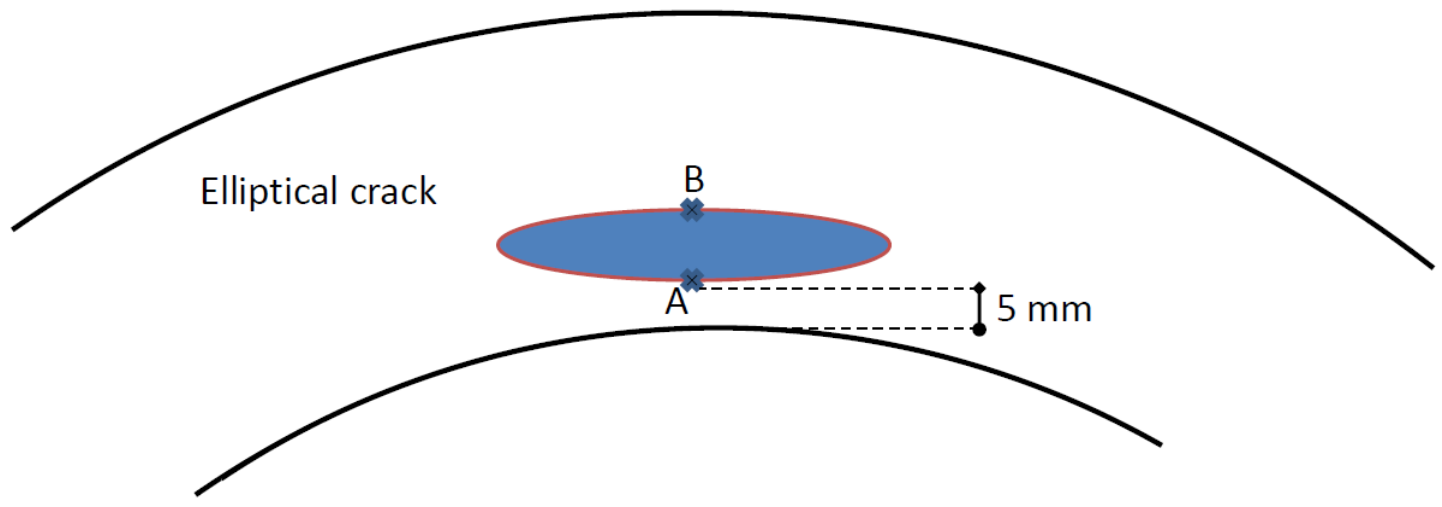

Fig. 1b Elliptical crack postulated in the study, both point A and B are considered in the calculation. 


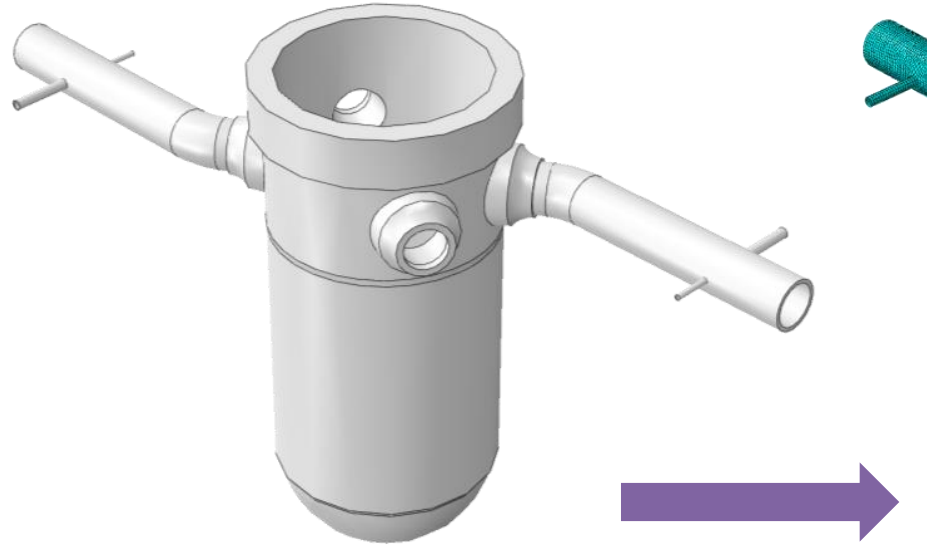

(a)

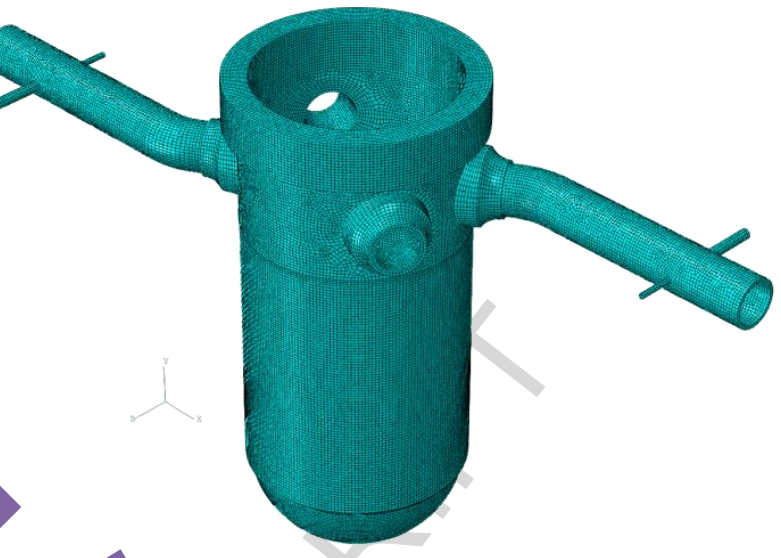

(b)

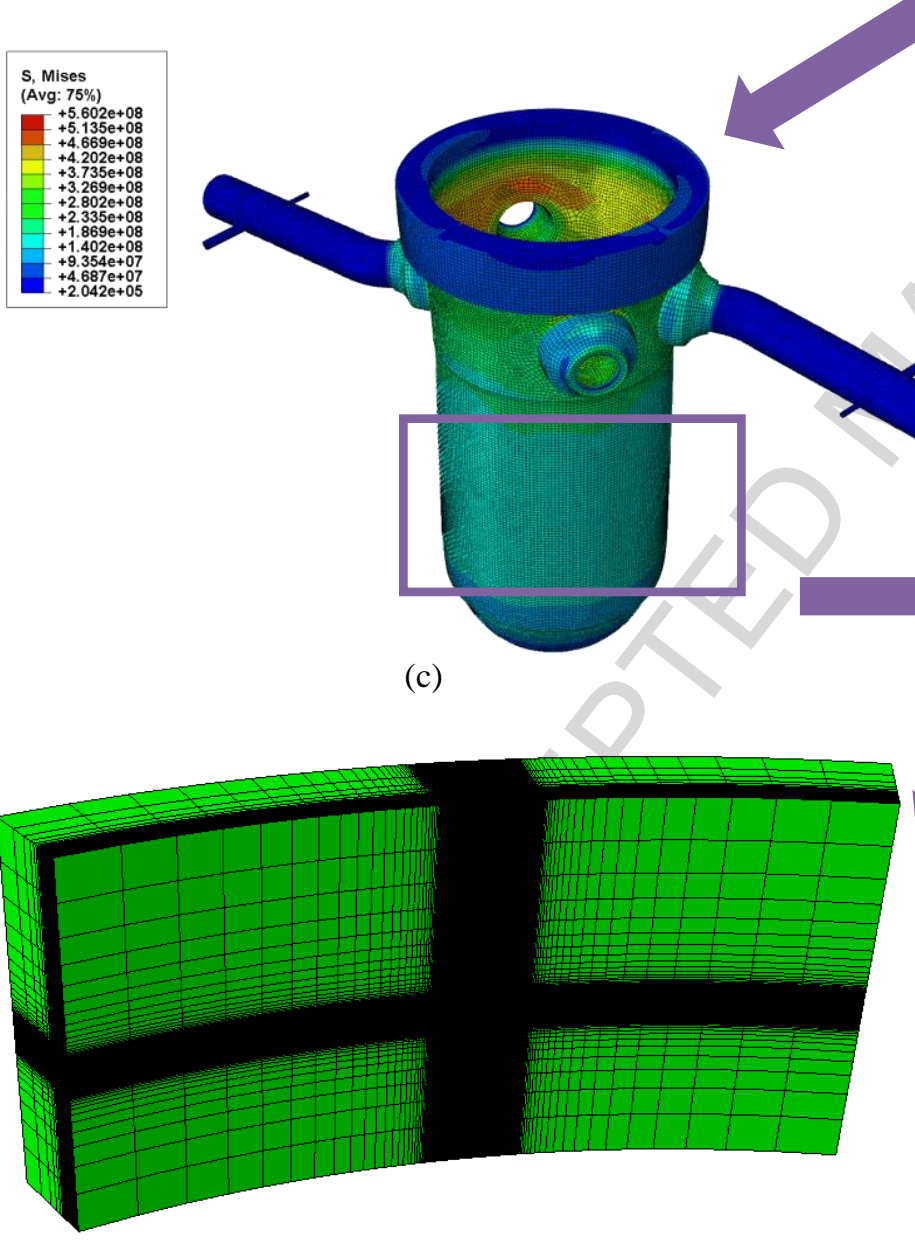

(e)

Fig. 2a the whole RPV model, Fig. 2b the meshed RPV, Fig. 2c stress distribution of the RPV, Fig. 2d XFEM assembling of the submodel RPV with an embedded crack, Fig. 2e XFEM modeling of an embedded crack in the submodeling. 


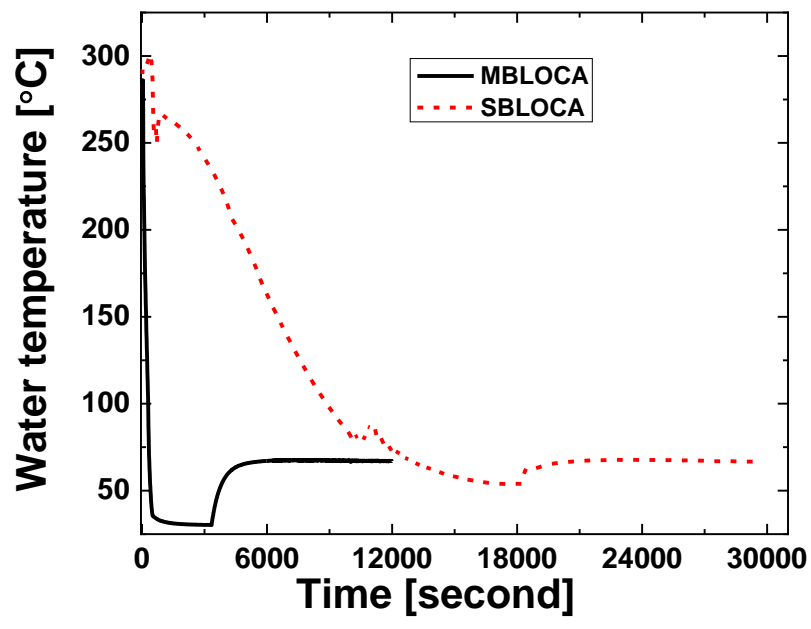

(a)

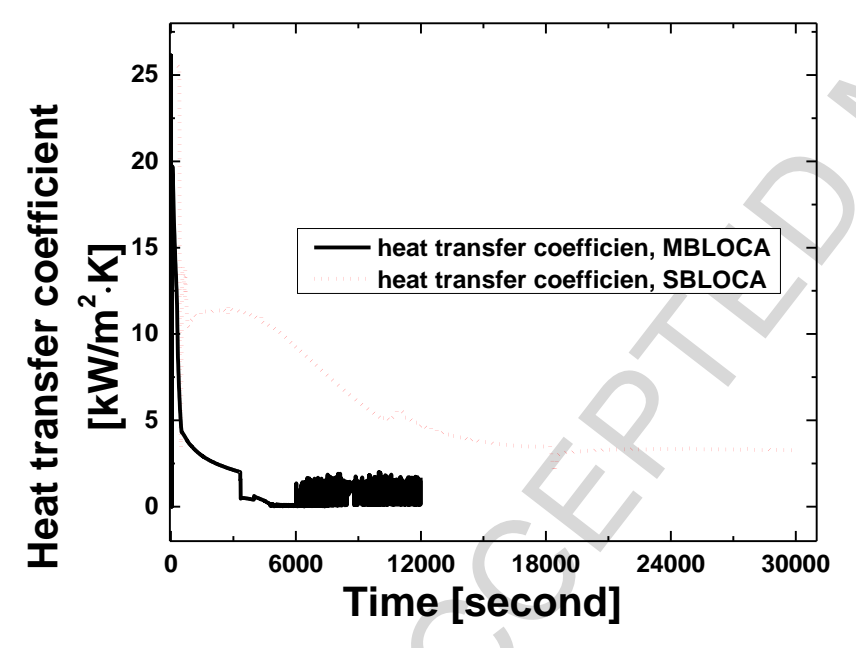

(c)

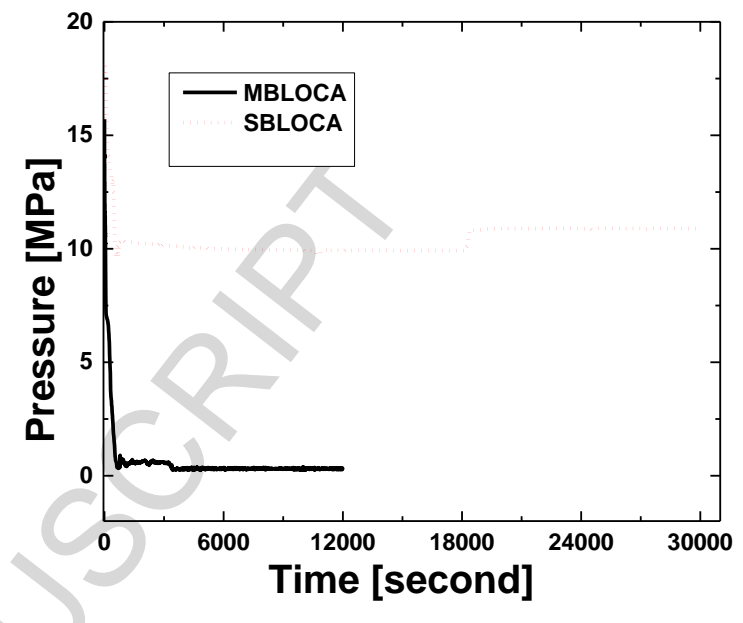

(b)

Fig. 3. MBLOCA and SBLOCA transients (a) water temperature history, (b) pressure history, (c) heat transfer coefficient history. 


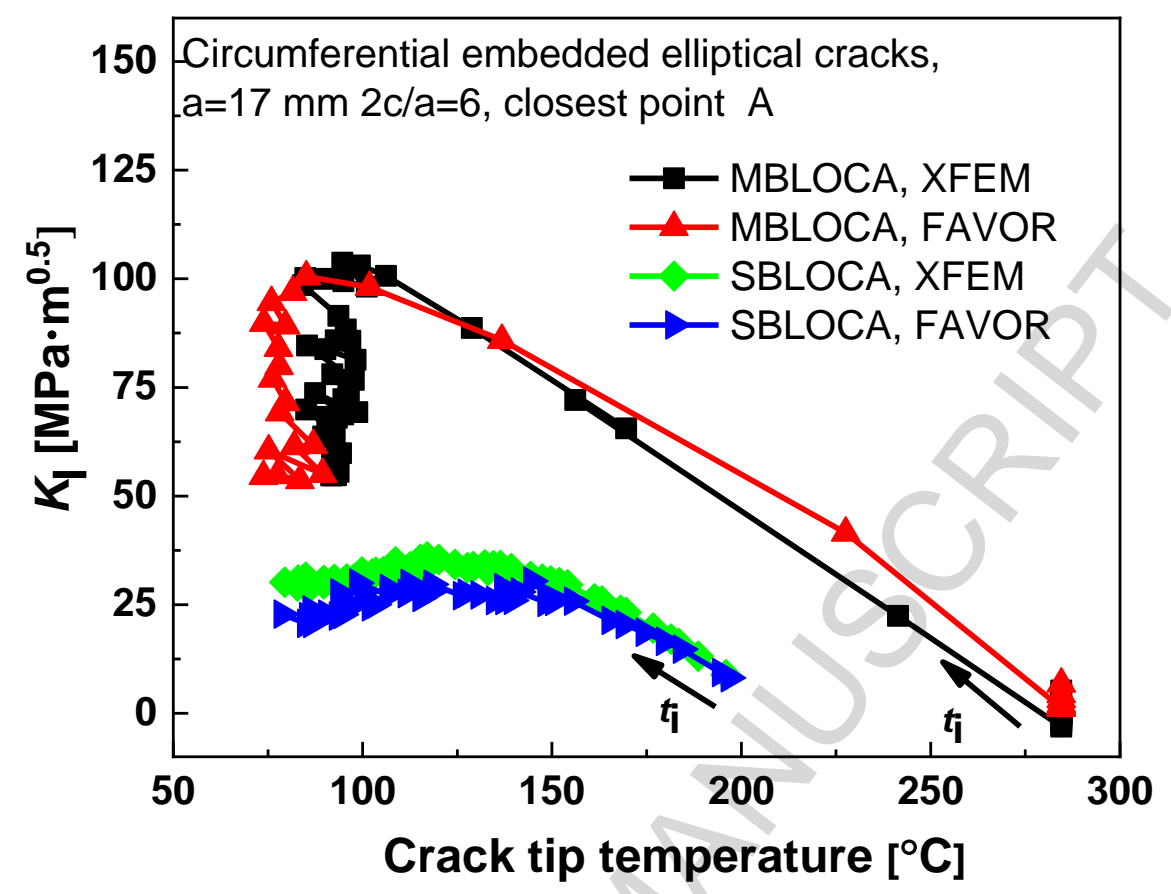

Fig. $4 \mathrm{~K}_{\mathrm{I}}$ for the embedded elliptical crack, MBLOCA and SBLOCA, point A is calculated by FAVOR and XFEM. 


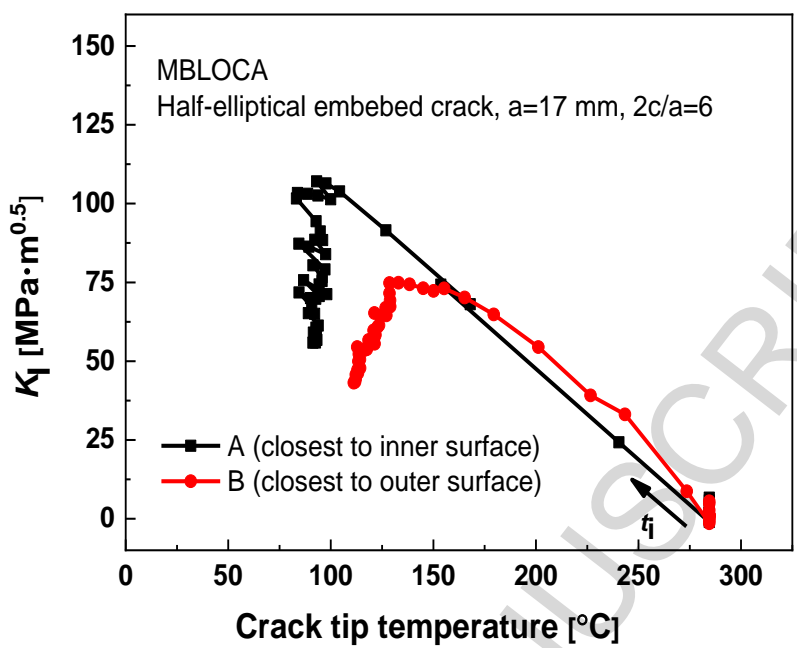

Fig. 5a $K_{I}$ for the half-elliptical crack, MBLOCA, both point A and B are calculated

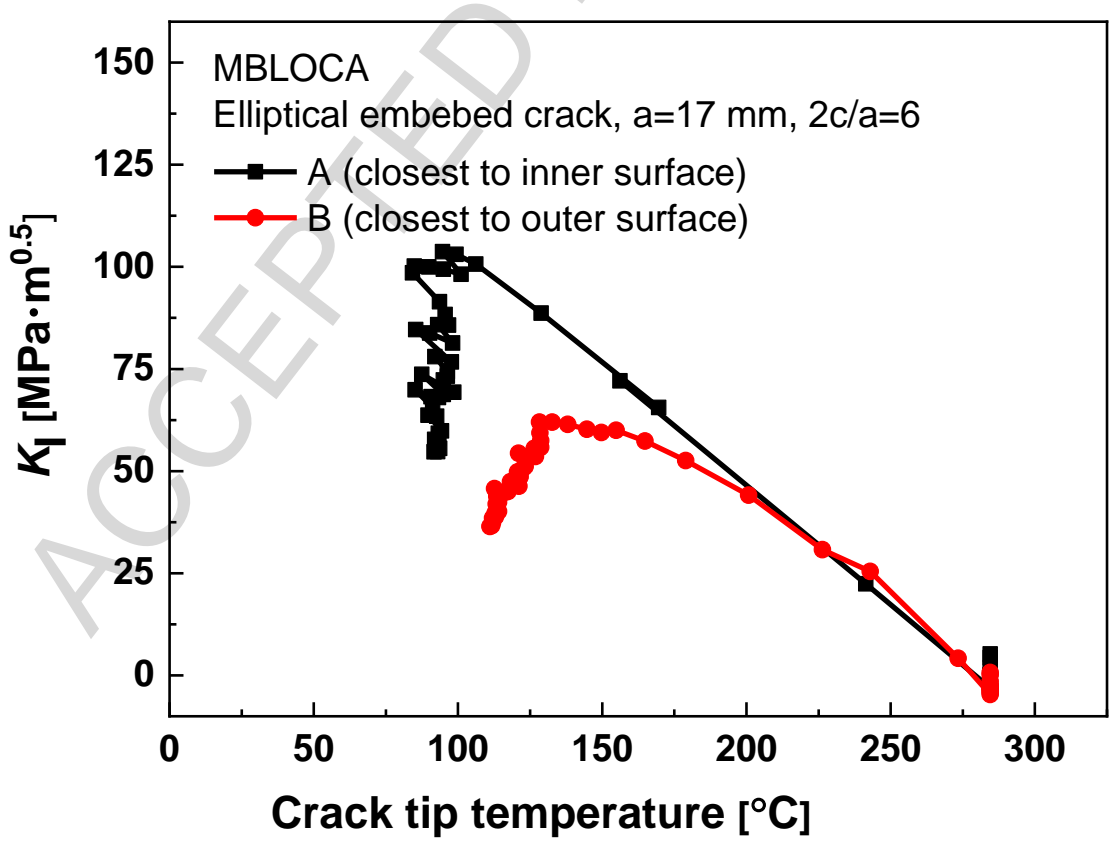

Fig. 5b $\mathrm{K}_{\mathrm{I}}$ for the elliptical crack, MBLOCA, both point A and B are calculated. 


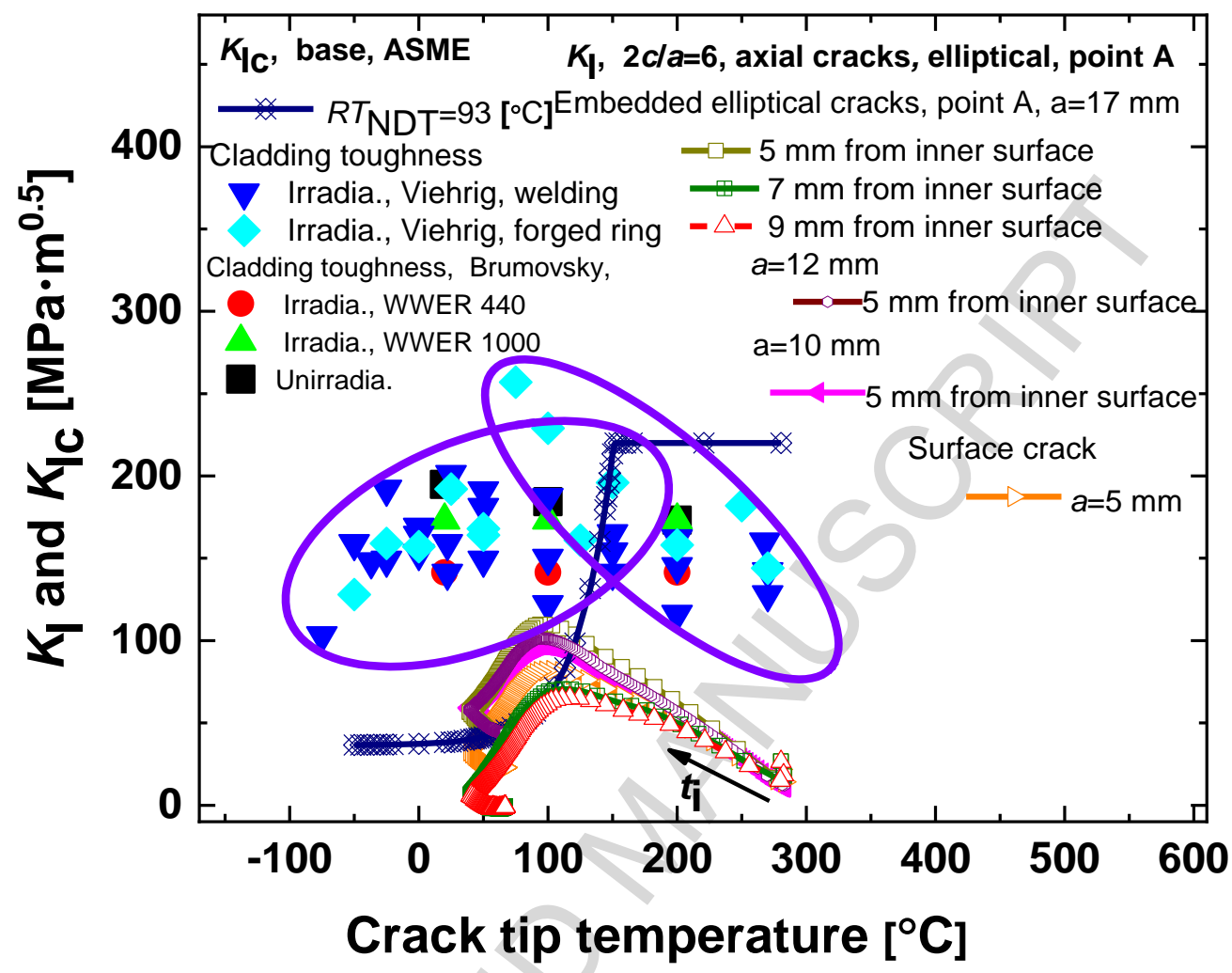

Fig. 6 Comparison of $K_{I}$ and $K_{I c}$ for both surface and embedded cracks subjected to MBLOCA, $K_{I c}$ for both base and cladding are compared. 


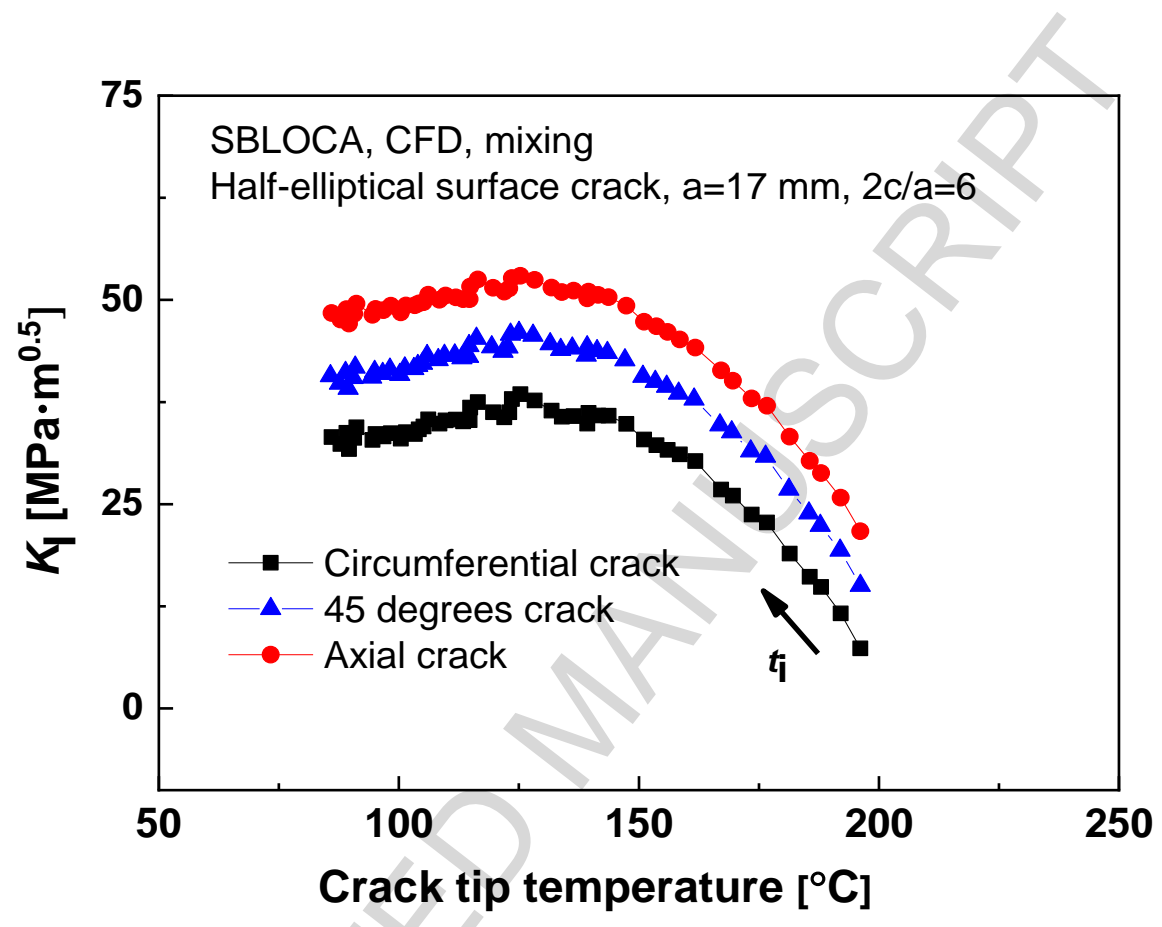

Fig. $7 \mathrm{~K}_{\mathrm{I}}$ for the circumferential, axial and 45 degree inclination cracks, SBLOCA 


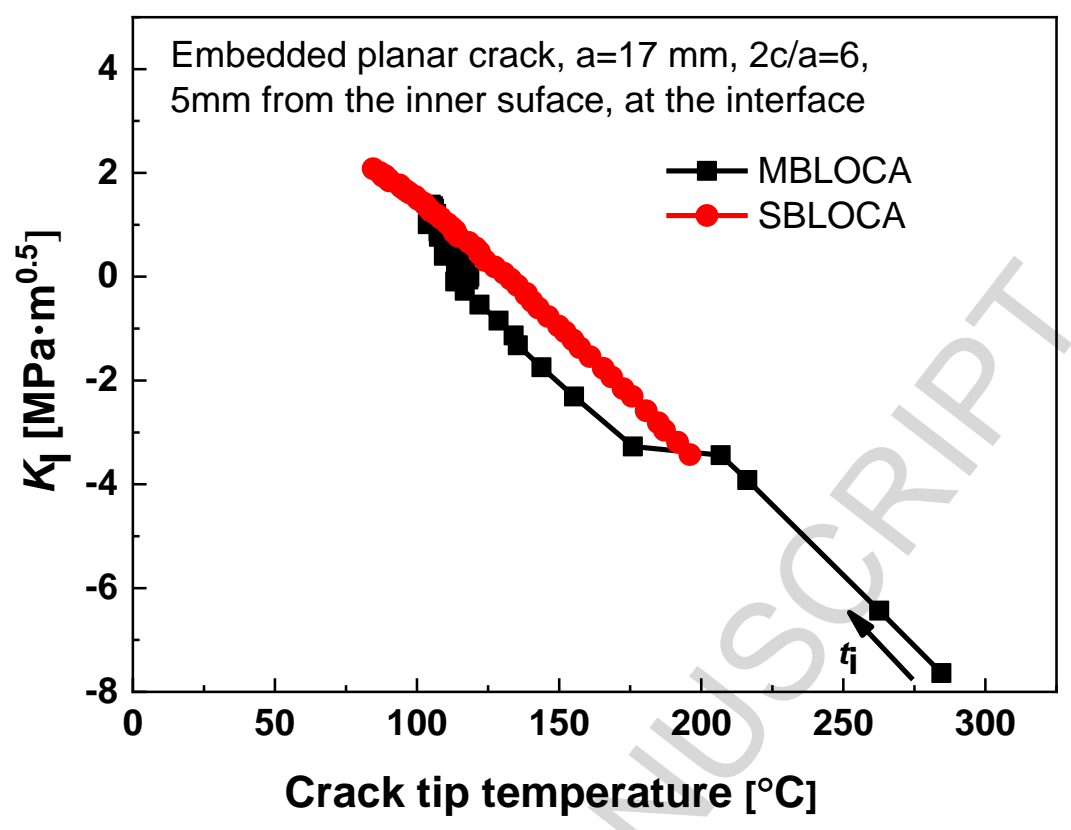

Fig. $8 \mathrm{~K}_{\mathrm{I}}$ for the embedded planar crack, MBLOCA and SBLOCA. 


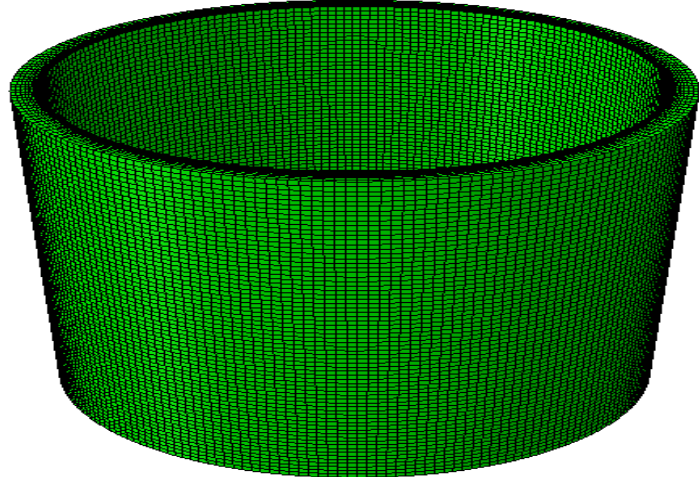

(a)

(b)

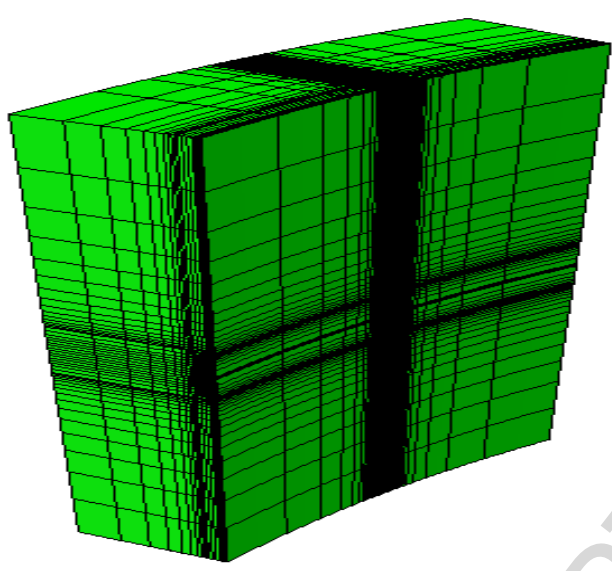

(c)

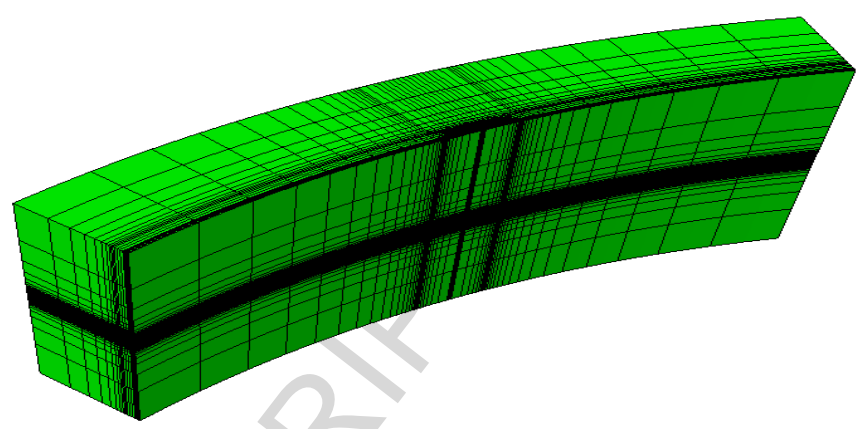

(b)

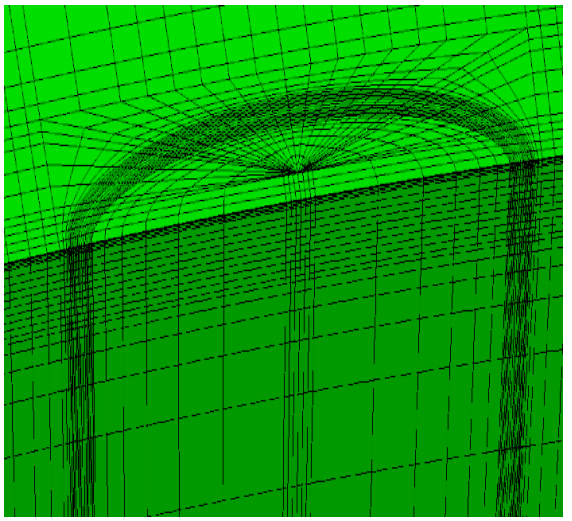

(d)

Fig. 9a Cylinder to introduce WRS in finite element simulation, Fig. 9b sub model of a circumferential crack in a cylinder, Fig. 9c sub model of an axial crack in a cylinder, Fig. 9d crack tip mesh. 


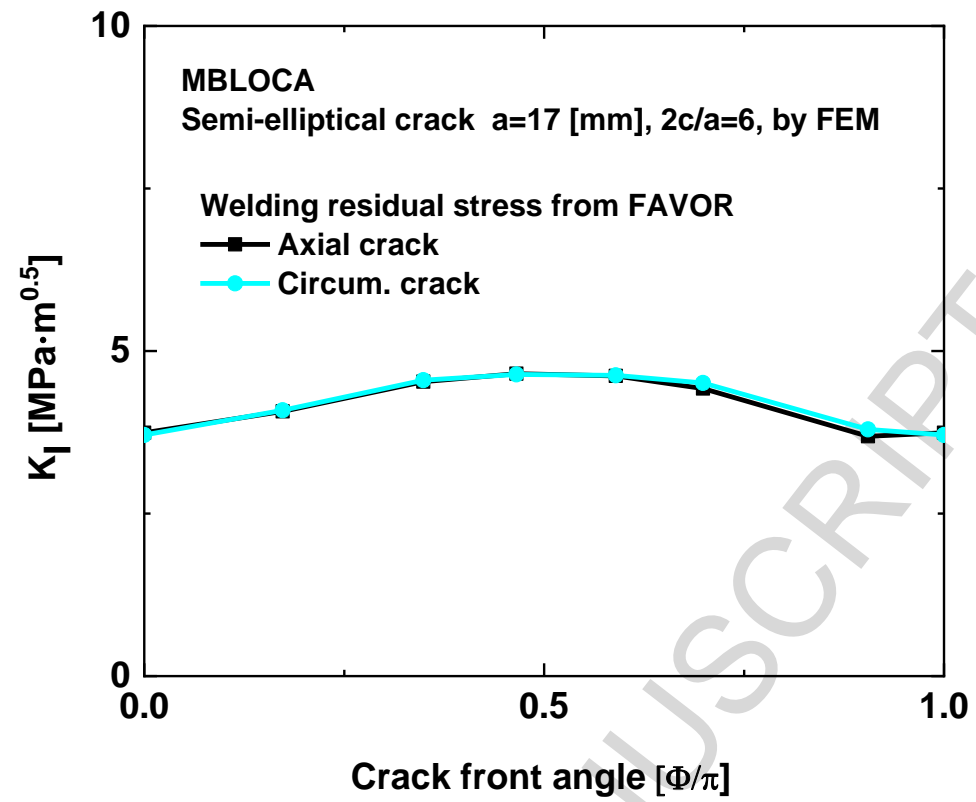

Fig. 10a $K_{I}$ of surface cracks due to the welding residual stress documented in FAVOR, calculated by 3D FEM.

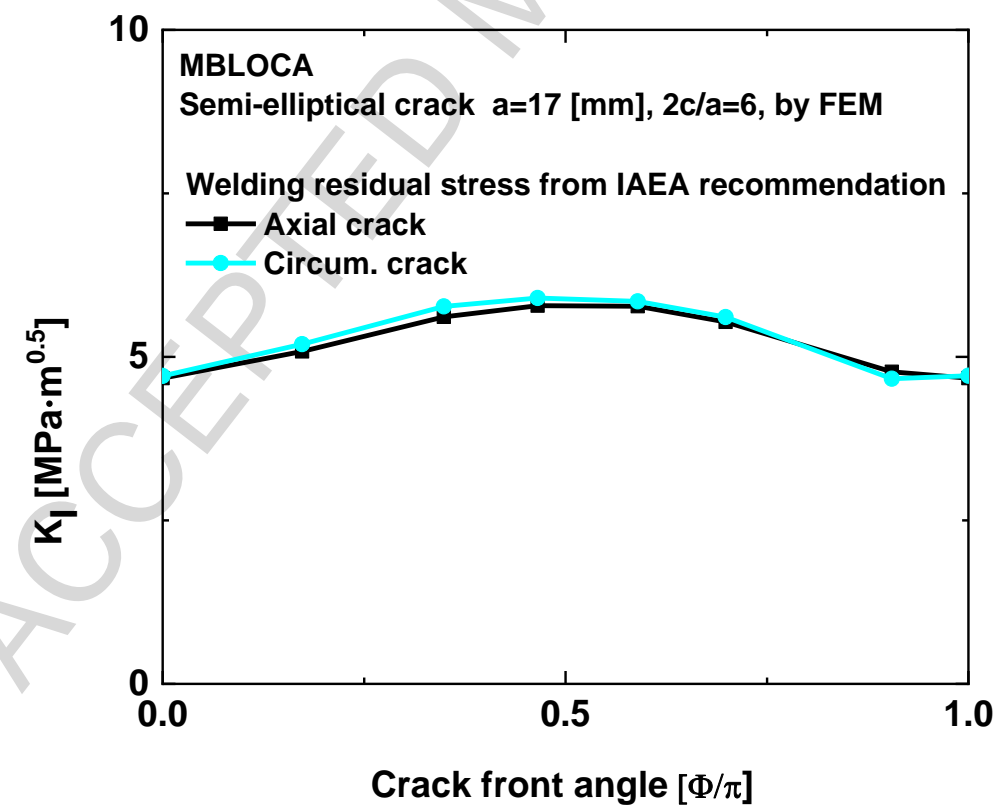

Fig. 10b $K_{I}$ of surface cracks due to the welding residual stress as documented in IAEA, calculated by 3D FEM. 


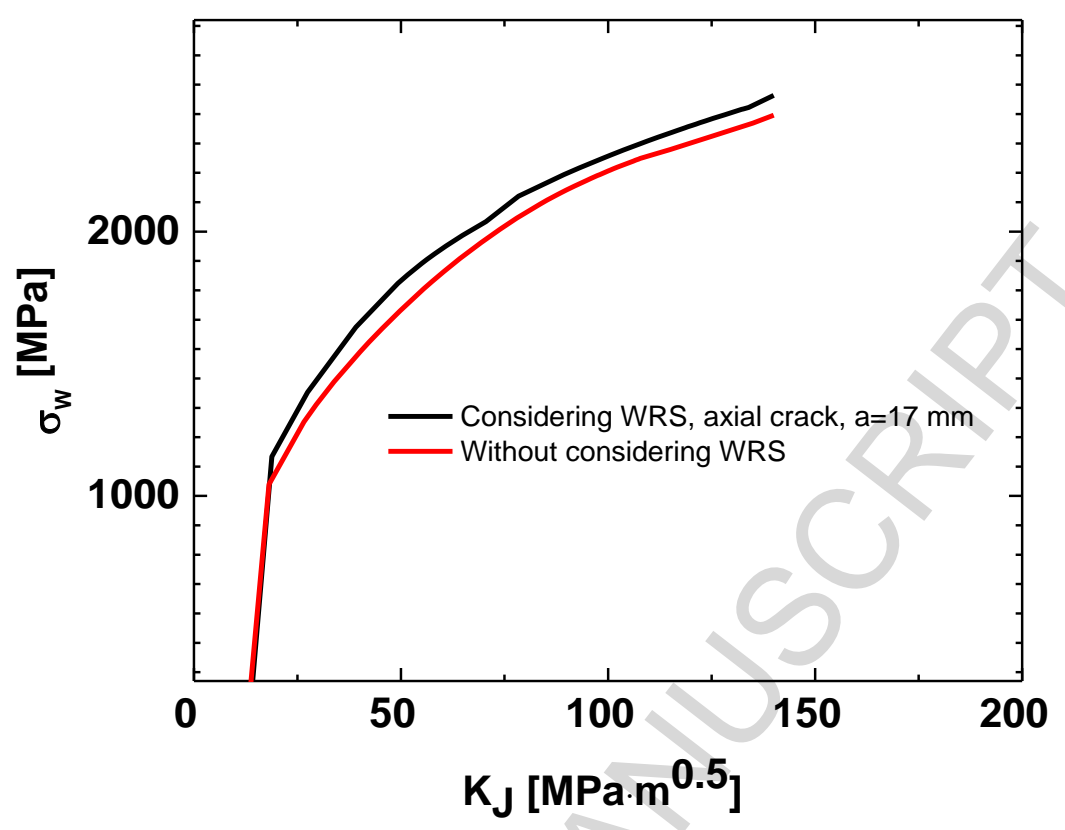

Fig. 11a Comparison of Weibull stress of the RPV with considering WRS and without considering WRS.

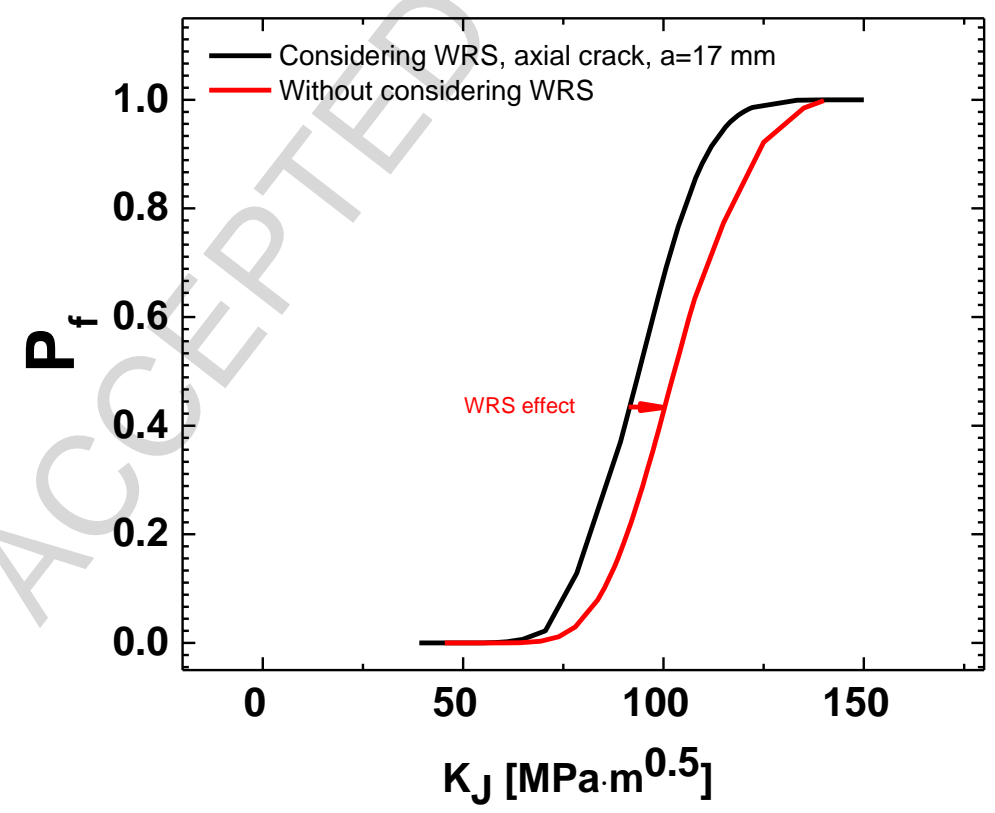

Fig. 11b Fracture probability of the RPV with considering WRS and without considering WRS . 


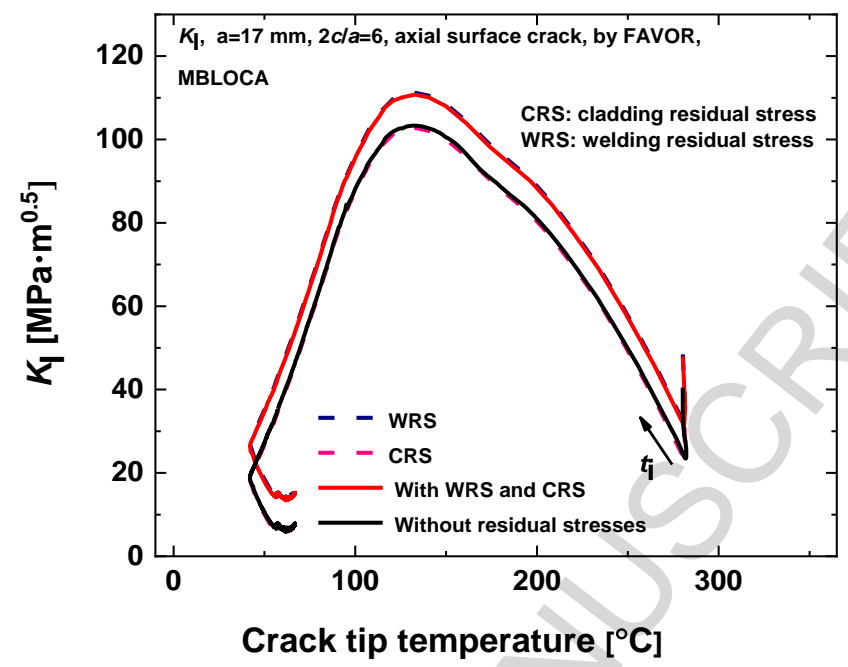

Fig.12a Influence of cladding (CRS) and welding residual stress (WRS) on $K_{I}$.

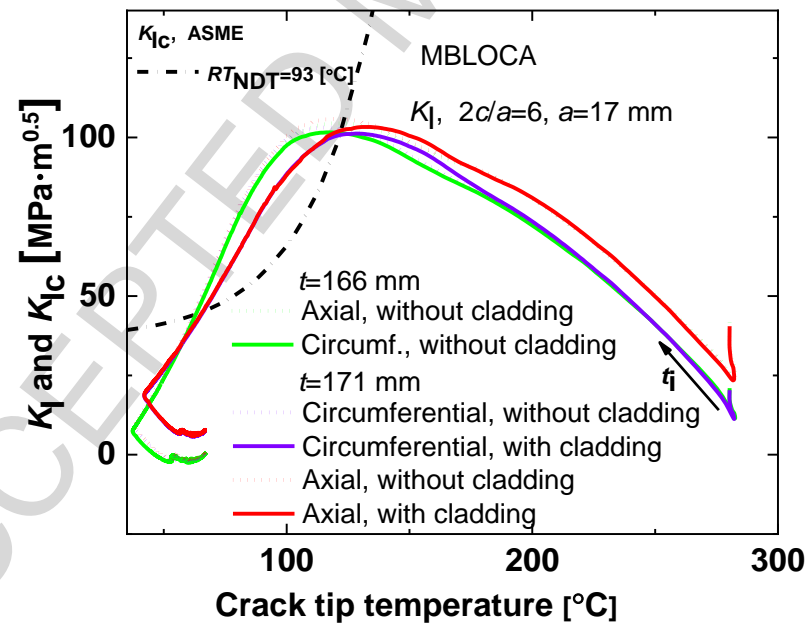

Fig. 12b $\mathrm{K}_{\mathrm{I}}$ of surface cracks with and without considering cladding, calculated by FAVOR. 
Highlights

1. It is unlikely for the embedded crack to propagate through the cladding

2. It is more appropriate to consider the outer surface point of the crack front

3. Considering welding residual stresses increases $K_{1}$ by about $5 \mathrm{MPa} \cdot \mathrm{m}^{0.5}$

4. Cladding/base interface residual stress has a negligible effect on $\mathrm{K}_{\mathrm{I}}$

5. Considering welding residual stress increases Weibull stress and fracture probability 